\title{
25 Research Soure \\ Research on the Development Status and Trends of Glaucoma Study Based on SCIE for Ten years
}

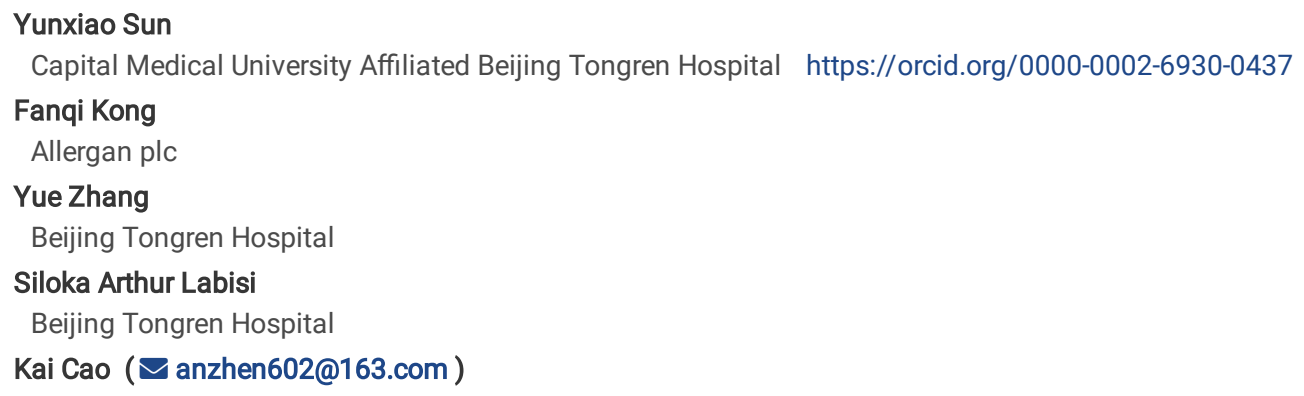




\section{Abstract}

Background To explore the development status and trends of glaucoma study from 2009 to 2018 based on SCIE.

Methods Searching for glaucoma-related articles published in SCIE in the last decade and describing the distribution of the time, region, author, author institution, journal and influence of articles. Meanwhile, we compared the publication of articles, the research hotspots among five years before and after 2009-2013, 2014-2018.

Results A total of 19,609 glaucoma-related articles were retrieved during 2009-2018 and the global SCIE articles have increased year by year from 2009 to 2017. The top five countries for articles were the United States, China, Japan, Germany and the England. The top three authors are Weinreb, R N, Aung, T and Jonas, J B. The journal with the largest number of published articles is INVESTIGATIVE OPHTHALMOLOGY VISUAL SCIENCE. It can be seen that glaucomarelated pathogenesis research, OCT and other imaging examinations in the diagnosis and treatment of glaucoma and glaucoma surgery have attracted much attention.

Conclusions In the past ten years, global glaucoma research has developed in a balanced manner, and the cooperation between various institutions and teams has become increasingly close. The research hotspots are still concentrated in the pathogenesis and diagnosis and treatment of glaucoma.

\section{Background}

Glaucoma is the leading cause of irreversible blindness in the world. Because of its high prevalence rate, high blindness rate and irreversible damage, it has become a major public health problem in China and the world. Searching and analyzing the related publications of glaucoma can comprehensively and intuitively understand the current research status and research hotspots, which plays an important role in the optimization of glaucoma research and clinical work.

This paper searches and analyzes the relevant literature data of glaucoma for the past ten years (2009-2018) in SCIE, and gives the distribution of the time, region, author, author institution, journal and influence of articles. Text-based mining software Thomson Data Analyzer (TDA), now renamed Derwent Data Analyzer (DDA) developed by the original Thomson Reuters Intellectual Property and Technology Business Unit (now renamed Kerui Wei'an), uses the scientific knowledge map theory method for literature data to conduct a panoramic analysis of data mining and visualization analysis from multiple perspectives (keyword co-occurrence, author collaboration, institutional cooperation, literature citation relationship, etc.). It will gain insight into the development trend of glaucoma research, emerging technologies, finding partners, determining research strategies, the development direction, and so on to provide some valuable evidence.

\section{Methods}

Data from 2009-2018 in SCIE (Science Citation Index Expanded, Science Citation Index Expanded Edition), search date 2019-3-29, search query: Subject: (glaucoma OR “ocular hypertension") AND Document type: (Article), where the "Subject” field contains: Title, Summary, Author Keywords, Keywords Plus. Import search records into reference management software to find duplicate records and exclude duplicate documents, media reports, meeting minutes and letters. Analyze the distribution of years, countries, authors, author institutions, journals and influence, etc of articles. Meanwhile, we compared the publication of articles, the research hotspots among five years before and after 2009-2013, 2014-2018.

\section{Results}

\section{Distribution of published year of literature}

A total of 19,609 glaucoma-related articles were retrieved during 2009-2018, and the distribution of year is shown in Table 1. The result shows that the global SCIE articles have increased year by year from 2009 to 2017, and the amount of articled in 2018 has decreased compared to 2017.

\section{Distribution of countries of articles (Top 10 countries in the number of articles)}

The top 10 countries are listed in Table 2, the top three countries are the United States, China and Japan, which respectively accounted for $32.439 \%$, $11.882 \%$ and $7.716 \%$ of the total number of articles in the past 10 years.

\section{The authors who have published the most articles in the top ten countries, their number of articles and their most cited articles}

The authors who have published the most articles in the top ten countries, their number of articles and their most cited articles are listed in Table 3 , and the top three are Robert N. Weinreb from the United States, Prof. Wang Ningli from China and professor ARAIE M from Japan.

\section{Distribution of authors (Top 10 authors)}

The top 20 authors during 2009-2018 are listed in Table 4. The top three are Weinreb, RN, Aung, T and Jonas, JB. 


\section{Author's co-occurrence figure}

The mean of co-occurrence matrices analyzed the top 50 authors in the number of articles. On this basis, the author's co-occurrence map was constructed and shown in Figure 1. This visualizes the author's clustering results and reflects the cooperation between the authors to some extent. The larger the circle in the figure, the larger the number of articles published by the author. Thicker the lines, more cooperation between authors. Due to the complicated cooperation between the authors, we increase the visual effect of the co-author map by setting the edge value of the map display to 12 (That is, the connection will be displayed only when the number of the author's cooperative publication is no less than 12).

\section{Distribution of authors}

Use SCI regulatory institution name and take the top 20 ins institutions. The top 3 institutions are the UNIVERSITY OF CALIFORNIA SYSTEM, UNIVERSITY OF LONDON and UNIVERSITY COLLEGE LONDON

\section{Author's institution (organization) co-occurrence map}

For the imported TDA data, we use " the Author Affiliations (Organization Only) " field, after the data cleaning, to take the top 50 institutions (organization only) to build a co-occurrence matrix, which visualizes the results of the author's institutions clustering and reflects the cooperation between institutions to some extent. The larger the circle in the figure, the larger the number of articles published by the organization. The thicker the lines, the higher the cooperation frequency between the organizations. Due to the complicated inter-institutional cooperation, we increase the visual effect of the co-occurrence map by setting the edge value to 20 (That is, the line will be only displayed when cooperation article numbers are no less than 20 ).

\section{Distribution of journals (Top 20 journals in which most of the articles were published)}

The top 20 journals in which most of the glaucoma articles were published in the SCIE during 2009-2018 are shown in Table 6 . The first journal is INVESTIGATIVE OPHTHALMOLOGY VISUAL SCIENCE, 1848 articles were published, accounting for $9.416 \%$ of the total articles in the past 10 years. The second is JOURNAL OF GLAUCOMA, 1558 articles were published, accounting for $7.938 \%$ of the total articles in the past 10 years; the third is PLOS ONE,773 articles were published, accounting for $3.938 \%$ of the total articles in the past 10 years.

\section{Distribution of funding agency (Top 20 funding agencies)}

The top 20 funding agencies are listed during the 2009-2018 in Table 7. The top three are RESEARCH TO PREVENT BLINDNESS, NATIONAL INSTITUTES OF HEALTH and NATIONAL NATURAL SCIENCE FOUNDATION OF CHINA.

\section{Distribution of Influence Factor (Based on the influencing factors in 2017)}

The influence factors of the Journals in which glaucoma articles were published during 2009-2018 are listed in Table 8. 19033 of 19609 articles have influence factors, 576 do not have influence factors. The number of articles is largest in the range of $3-5$ points, which is up to 5679 , accounting for $28.961 \%$ of the total number of articles.

\section{Distribution of keywords}

Based on the keyword (author's'), after the data is cleaned and processed, the keywords appeared in more than 100 articles are obtained and shown in Table 9. The top three keywords are glaucoma, intraocular pressure and OCT.

\section{Keywords co-occurrence map}

Build the co-occurrence matrix by the top 50 keywords, on the basis of which we make a co-occurrence map. So, we can visualize the clustering results. The larger the circle in the figure, the larger the number of the article. The thicker the line, and the stronger the correlation between keywords. The keywords of the cross line can be seen as discussion hotspots (i.e. all the keywords given in the figure). Since the co-occurrence relationship between keywords is complicated, we increase the visual effect of the co-occurrence map by setting the edge value of the map to 5 (That is, the inter-keyword connection will be displayed only when they appeared simultaneously in no less than 5 articles).

\section{Discussion}

\section{Discussion of publication status and regularities of distribution of glaucoma articles in the past decade}

In this paper, glaucoma and high intraocular pressure are search terms. 2009-2018 is the search span. A total of 19,609 articles were retrieved from SCl, 8489, between 2009-2013, 11120, between 2014-2018. A table shows that from 2009 to 2017, global SCIE publications increased year by year. Yet 2018's publications' amount declined compared with 2017. It may be because the search time is March, 2019. Some articles of 2018 have not been included. 
The United States, China, and Japan have become the top three countries in the number of articles, leading the development of intercountry glaucoma research. This article focuses on the authors who have published the most articles in the top ten countries and the most cited articles, aiming to explore the teams leading the development of glaucoma research, their outstanding contributions and their primary research areas, providing direction for intercountry cooperation. Professor Weinreb RN from the United States is the first, who has published a total of 325 articles in the past 10 years. The most cited article is Retinal Nerve Fiber Layer Imaging with Spectral-Domain Optical Coherence Tomography A Variability and Diagnostic Performance Study ${ }^{[1]}$, which is quoted as high as 276 times. Professor Weinreb RN notes that spectral-domain OCT shows less variability than time-domain OCT in the measurement of the retinal nerve fiber layer in this article, which suggests the spectral-domain OCT is in more meaningful in assessment of glaucoma progression (by measuring the optic nerve fiber layer thickness).It guides the application of OCT in the assessment of glaucoma progression is with an important clinical significance. Japanese professor ARAIE M has published 117 articles in the past 10 years. The most cited one is Effects of Age, Sex, and Axial Length on the ThreeDimensional Profile of Normal Macular Layer Structures ${ }^{[2]}$, cited 107 times. In this paper, professor ARAIE M points out that the structure of normal macular area is related to age, gender and axial length, suggesting that these factors need to be considered when using the spectral-domain OCT to study the structure of the macular area on patients with retinopathy and glaucoma. It guides the clinical application of OCT and accurate structural measurement. The sixth article from Korean professor team of Eun Ji Lee applies depth imaging technique- spectral domain OCT and the whole thickness of the lamina cribrosa can be clearly visualized. This technology can promote the study of lamina cribrosa in glaucoma patients, and also provide a method for studying the mechanism of optic neuropathy. The seventh article from Indian professor RAO HL finds that the use of RTVueOCT to measure retinal nerve fiber layer and retinal macular thickness can significantly better detect glaucoma visual field defects than the papilla of the optic nerve. These four heavyweight articles thus confirm countries follow the application of OCT in the diagnosis and treatment of glaucoma and glaucoma pathogenesis.

Professor Wang Ningli from China has published 136 articles in the past 10 years. The most cited article is Cerebrospinal Fluid Pressure in Glaucoma A Prospective Study ${ }^{[3]}$, which has been cited for up to 232 times. Professor Wang Ningli firstly discovers that the intracranial pressure of normal-tension glaucoma patient is low and the pressure difference across the lamina cribrosa is high through prospective study, suggesting that the two factors of intraocular pressure and intracranial pressure should be considered in the diagnosis and treatment of glaucoma. The treatment should aim at balancing the pressure gradient of the eye, and the study established the theory of optic nerve damage caused by inadequate pressure gradient of the eye for the first time in the world, which is a milestone.

In epidemiological studies, Professor JONAS JB collects the cause of vision loss in the globe during $1990-2010^{[4]}$. In 2010 , the world had $65 \%$ of blind patients, and $76 \%$ of moderate to severe visual impairment patients may have a cause that can be prevented or treated. The causes of blindness vary among patients in different regions, but women worldwide are more likely than men to have blind or moderate to severe visual impairment due to cataracts and macular degeneration. In order to guide public health policy, systematic analysis of the proportion of causes have been ongoing in the past few years, which has a guiding significance for the resource allocation of ophthalmic disease control. The fifth Singapore - India - China cohort study compares the incidence, risk factors and effects of major ophthalmic diseases among Chinese and Indian Malaysian ethnic groups ${ }^{[5]}$. The study helps to understand the different environmental and genetic impacts of different ethnic groups. In addition, although not in the top ten countries, the Singapore Institute of Ophthalmology published a META study Global prevalence of glaucoma and projections of glaucoma burden through 2040: a systematic review and metaanalysis $^{[6]}$, the most cited article in the past decade. This paper systematically analyzes 50 studies data of population-based studies and predicts the number of affected in 2020 and 2040. The study concludes that global prevalence rate of glaucoma in $40-80$-year-old people is $3.54 \%$. Highest POAG prevalence is in Africa. Highest PACG prevalence is in Asia. In 2040, the number of glaucoma patients worldwide will increase to 111.8 million. The study is important for the design of glaucoma screening, treatment and related public health strategies.

The ninth and tenth study from Turkish and Italian respectively are related to drug treatment. One proposes that in exfoliation glaucoma, whether the administration is in morning or evening, the group of a fixed combination of bimatoprost and timolol can control 24 hours intraocular pressure better than any group of a single medicine ${ }^{[7]}$. Another suggests that dithiocarbamates can inhibit carbonic anhydrase activity and exhibit an effect of effectively reducing intraocular pressure in vivo. This new carbonic anhydrase inhibitor provides a new drug candidate for anti-glaucoma drugs ${ }^{[8]}$.

The authors and articles of the above ten countries represent the development of direction of epidemiology, diagnosis and treatment of glaucoma in the past decade. In addition, the top 3 countries that have most articles published are the United States, China and Japan, which accounted for nearly $32.439 \%$, $11.882 \%$ and $7.716 \%$ of the total number of articles respectively. In the five years before and after the comparison, it can be seen that the number of articles from the United States has declined in the past five years, and the number of articles in several Asian countries has increased significantly, such as China, South Korea, Japan, and India. Among the top 20 authors, the number of authors from Europe and America and authors from Asia is 1:1. And the development in all regions of the world is comparable. Exchanges and cooperation between agencies can promote the progress of science. Before and after the comparison, the frequency of cooperation among authors in the core author group has increased in the past five years, and the frequency of cooperation between Asian countries and Western countries has also increased significantly.

The distribution of fund agencies can show that the authority maintains a leading position: Research to Prevent Blindness (RPB), National Institutes of Health (NIH), National Natural Science Foundation of China, and the National Natural Science Foundation of China has increased its funding for the past five years, leaps to first in the ranking. In the past five years, the number of Japanese funded articles has increased significantly. The agencies are the Japan Ministry of Education, Culture, Sports and Science, Santen, Japan, and the Japan Society for Promotion Science.

\section{Glaucoma research and hotspots analysis}


The keyword is the most accurate and concise disclosure of the content of the article. It reflects the main research content of the paper to a large extent and implies the research status, hotspots and development laws of the subject. Based on the author's keywords, this paper performs statistics after data cleaning and takes the keywords appeared in more than 100 articles, as shown in Table 9. The top three keywords are glaucoma, intraocular pressure and OCT. Build the co-occurrence matrix by the top 50 keywords, on the basis of which we make a co-occurrence map. So, we can visualize the clustering results. The larger the circle in the figure, the larger the number of the article. The thicker the line, and the stronger the correlation between keywords. The keywords of the cross line can be seen as discussion hotspots. It can be seen from Figure 3 that the focus of glaucoma research in the past decade is mainly on: (1) glaucoma and intraocular pressure; (2) glaucoma and OCT; (3) glaucoma and retinal ganglion cells; (4) glaucoma and vision; (5) glaucoma and trabeculectomy and so on. It can be seen that glaucoma-related pathogenesis research, OCT and other imaging examinations in the diagnosis and treatment of glaucoma and glaucoma surgery have attracted much attention. Comparison between the keywords hotspot of before and after five years can reveal that during 2009-2013, the hotspots were CCT, prostaglandin derivatives, indicating the attention on the accuracy of intraocular pressure measurement and prostaglandin anti-glaucoma drugs. During 2014-2018, the hotspots was trabecular meshwork indicating more focus on the function and structure of the trabecular meshwork.

This research belongs to the exploratory research based on published literature, and it has certain limitations. Based on the frequency of keyword occurrence, the research hotspots may miss the latest hotspots. However, it basically conforms to the development law of the international glaucoma field in the past ten years.

\section{Conclusion}

In the past ten years, global glaucoma research has developed in a balanced manner, and the cooperation between various institutions and teams has become increasingly close. The research hotspots are still concentrated in the pathogenesis and diagnosis and treatment of glaucoma. This study is based on the analysis of large sample bases and has important reference value for revealing the macroscopic situation in the glaucoma research field. We believe that strengthening international exchanges and cooperation will be an important way to advance scientific research in the field of glaucoma.

\section{List Of Abbreviations}

SCIE: Science Citation Index Expanded

OCT: Optical Coherence Tomography

TDA: Thomson Data Analyzer

$D D A$ : Derwent Data Analyzer

\section{Declarations}

Ethics approval and consent to participate: Not applicable

Consent for publication: Not applicable

Availability of data and materials: The datasets used and/or analysed during the current study are available from the corresponding author on reasonable request.

Competing interests: The authors declare that they have no competing interests

Funding: This work was supported by National Natural Science Foundation of China (GZR-2012-009); The role of the funding was in the collection and analysis of data and in writing the manuscript.

Authors' contributions:Study conceptualization and designing: Yunxiao Sun and Kai Cao; data collection: Yunxiao Sun, Fanqi Kong and Yue Zhang; interpretation and analysis of data: Yunxiao Sun and Siloka Arthur Labisi; drafting of the manuscript: Yunxiao Sun; critical revision of the manuscript: Kai Cao. All authors have read and approved the manuscript.

Acknowledgements: None

\section{References}

[1].Leung, C. K., et al., Retinal nerve fiber layer imaging with spectral-domain optical coherence tomography: a variability and diagnostic performance study. Ophthalmology, 2009. 116(7): p. 1257-63, 1263.e1-2.

[2].Ooto, S., et al., Effects of age, sex, and axial length on the three-dimensional profile of normal macular layer structures. Invest Ophthalmol Vis Sci, 2011. 52(12): p. 8769-79.

[3].Ren, R., et al., Cerebrospinal fluid pressure in glaucoma: a prospective study. Ophthalmology, 2010. 117(2): p. $259-66$.

[4].Bourne, R. R., et al., Causes of vision loss worldwide, 1990-2010: a systematic analysis. Lancet Glob Health, 2013. 1(6): p. e339-49. 
[5].Lavanya, R., et al., Methodology of the Singapore Indian Chinese Cohort (SICC) eye study: quantifying ethnic variations in the epidemiology of eye diseases in Asians. Ophthalmic Epidemiol, 2009. 16(6): p. 325-36.

[6].Barkana, Y. and S. Dorairaj, Re: Tham et al.: Global prevalence of glaucoma and projections of glaucoma burden through 2040: a systematic review and meta-analysis (Ophthalmology 2014;121:2081-90). Ophthalmology, 2015. 122(7): p. e40-1.

[7].Konstas, A. G., et al., Twenty-four-hour intraocular pressure control with bimatoprost and the bimatoprost/timolol fixed combination administered in the morning, or evening in exfoliative glaucoma. Br J Ophthalmol, 2010. 94(2): p. 209-13.

[8].Carta, F., et al., Dithiocarbamates strongly inhibit carbonic anhydrases and show antiglaucoma action in vivo. J Med Chem, 2012. 55(4): p. 1721-30.

\section{Tables}

Table 1 Relevant articles and distribution of published year of glaucoma articles during 2009-2018

\begin{tabular}{ccc}
\hline Year & Numbers of articles & $\% / 19609$ \\
\hline 2018 & 2,297 & $11.714 \%$ \\
2017 & 2,383 & $12.153 \%$ \\
2016 & 2,306 & $11.760 \%$ \\
2015 & 2,081 & $10.612 \%$ \\
2014 & 2,053 & $10.470 \%$ \\
2013 & 1,933 & $9.858 \%$ \\
2012 & 1,791 & $9.134 \%$ \\
2011 & 1,774 & $9.047 \%$ \\
2010 & 1,531 & $7.808 \%$ \\
2009 & 1,460 & $7.446 \%$ \\
\hline
\end{tabular}

Table 2 Top 10 countries in the number of articles during 2009-2018

\begin{tabular}{|c|c|c|c|c|c|c|}
\hline \multirow[t]{2}{*}{ Rank } & \multicolumn{2}{|c|}{$2009-2018$} & \multicolumn{2}{|c|}{ 2009-2013 } & \multicolumn{2}{|c|}{$2014-2018$} \\
\hline & Country & $\% / 19609$ & Country & $\% / 8489$ & Country & $\% / 11120$ \\
\hline \multirow[t]{2}{*}{1} & USA & 32.439 & USA & 34.068 & USA & 31.196 \\
\hline & & $\%$ & & $\%$ & & $\%$ \\
\hline \multirow[t]{2}{*}{2} & PEOPLES R & $11.882 \%$ & PEOPLES R & 9.860 & PEOPLES R & 13.426 \\
\hline & CHINA & & CHINA & $\%$ & CHINA & $\%$ \\
\hline \multirow[t]{2}{*}{3} & JAPAN & $7.716 \%$ & GERMANY & 8.022 & JAPAN & $8.210 \%$ \\
\hline & & & & $\%$ & & \\
\hline \multirow[t]{2}{*}{4} & GERMANY & $7.558 \%$ & ENGLAND & 7.339 & GERMANY & $7.203 \%$ \\
\hline & & & & $\%$ & & \\
\hline \multirow[t]{2}{*}{5} & ENGLAND & $7.231 \%$ & JAPAN & 7.068 & ENGLAND & $7.149 \%$ \\
\hline & & & & $\%$ & & \\
\hline \multirow[t]{2}{*}{6} & SOUTH & $5.538 \%$ & AUSTRALIA & $4.900 \%$ & SOUTH & $6.718 \%$ \\
\hline & KOREA & & & & KOREA & \\
\hline \multirow[t]{2}{*}{7} & INDIA & $4.651 \%$ & SOUTH & 3.993 & INDIA & $5.225 \%$ \\
\hline & & & KOREA & $\%$ & & \\
\hline \multirow[t]{2}{*}{8} & AUSTRALIA & $4.631 \%$ & INDIA & 3.899 & TURKEY & $4.703 \%$ \\
\hline & & & & $\%$ & & \\
\hline 9 & TURKEY & $4.090 \%$ & CANADA & $3.770 \%$ & AUSTRALIA & $4.424 \%$ \\
\hline 10 & ITALY & $3.656 \%$ & ITALY & $3.770 \%$ & ITALY & $3.570 \%$ \\
\hline
\end{tabular}

Table 3 The authors who have published the most articles in the top ten countries, their number of articles and their most cited articles 


\begin{tabular}{|c|c|c|c|c|c|c|c|}
\hline Rank & Country & Author & $\begin{array}{l}\text { Number } \\
\text { of } \\
\text { articles }\end{array}$ & Most cited articles & $\begin{array}{l}\text { Cited } \\
\text { times }\end{array}$ & $\begin{array}{l}\text { published } \\
\text { time }\end{array}$ & Journal \\
\hline 1 & USA & $\begin{array}{l}\text { WEINREB } \\
\text { RN }\end{array}$ & 325 & $\begin{array}{l}\text { Retinal Nerve Fiber Layer Imaging with Spectral- } \\
\text { Domain Optical Coherence Tomography A } \\
\text { Variability and Diagnostic Performance Study }\end{array}$ & 276 & Jul-09 & OPHTHALMOLOGY \\
\hline 2 & $\begin{array}{l}\text { PEOPLES } \\
\text { R CHINA }\end{array}$ & $\begin{array}{l}\text { WANG } \\
\text { NL }\end{array}$ & 136 & $\begin{array}{l}\text { Cerebrospinal Fluid Pressure in Glaucoma A } \\
\text { Prospective Study }\end{array}$ & 232 & Feb-10 & OPHTHALMOLOGY \\
\hline 3 & JAPAN & ARAIE M & 117 & $\begin{array}{l}\text { Effects of Age, Sex, and Axial Length on the Three- } \\
\text { Dimensional Profile of Normal Macular Layer } \\
\text { Structures }\end{array}$ & 107 & Nov-11 & $\begin{array}{l}\text { INVESTIGATIVE } \\
\text { OPHTHALMOLOGY } \\
\text { \& VISUAL } \\
\text { SCIENCE }\end{array}$ \\
\hline 4 & GERMANY & JONAS JB & 184 & $\begin{array}{l}\text { Causes of vision loss worldwide, 1990-2010: a } \\
\text { systematic analysis }\end{array}$ & 399 & Dec-13 & $\begin{array}{l}\text { LANCET GLOBAL } \\
\text { HEALTH }\end{array}$ \\
\hline 5 & ENGLAND & $\begin{array}{l}\text { FOSTER } \\
\text { PJ }\end{array}$ & 76 & $\begin{array}{l}\text { Methodology of the Singapore Indian Chinese } \\
\text { Cohort (SICC) Eye Study: Quanttile ethnic } \\
\text { variations in the epidemiology of eye diseases in } \\
\text { Asians }\end{array}$ & 179 & $\begin{array}{l}\text { NOV- } \\
\text { DEC } \\
2009\end{array}$ & $\begin{array}{l}\text { OPHTHALMIC } \\
\text { EPIDEMIOLOGY }\end{array}$ \\
\hline 6 & $\begin{array}{l}\text { SOUTH } \\
\text { KOREA }\end{array}$ & PARK KH & 184 & $\begin{array}{l}\text { Visualization of the Lamina Cribrosa Using } \\
\text { Enhanced Depth Imaging Spectral-Domain Optical } \\
\text { Coherence Tomography }\end{array}$ & 119 & Jul-11 & $\begin{array}{l}\text { AMERICAN } \\
\text { JOURNAL OF } \\
\text { OPHTHALMOLOGY }\end{array}$ \\
\hline
\end{tabular}

Table 4 Top 20 Authors who published most articles during 2009-2018.

\begin{tabular}{clc}
\hline Rank & Author & Numbers \\
\hline 1 & Weinreb, RN & 325 \\
2 & Aung, T & 244 \\
3 & Jonas, JB & 184 \\
4 & Park, KH & 184 \\
5 & Ritch, R & 175 \\
6 & Liebmann, JM & 161 \\
7 & Medeiros, FA & 154 \\
8 & Wong, TY & 154 \\
9 & Zangwill, LM & 141 \\
10 & Wang, NL & 136 \\
11 & Sun, XH & 123 \\
12 & Friedman, DS & 120 \\
13 & Park, CK & 118 \\
14 & Araie, M & 117 \\
15 & Pasquale, LR & 108 \\
16 & Kim, CY & 105 \\
17 & Pfeiffer, N & 105 \\
18 & Schuman, JS & 100 \\
19 & Jeoung, JW & 96 \\
20 & Nakazawa, T & 95 \\
\hline
\end{tabular}

Table 5 Top 20 institutions that published articles most during 2009-2018 


\begin{tabular}{|c|c|c|c|}
\hline Rank & Author's institution & Number of articles & $\% / 19609$ \\
\hline 1 & UNIVERSITY OF CALIFORNIA SYSTEM & 1,060 & $5.406 \%$ \\
\hline 2 & UNIVERSITY OF LONDON & 664 & $3.386 \%$ \\
\hline 3 & UNIVERSITY COLLEGE LONDON & 587 & $2.994 \%$ \\
\hline 4 & JOHNS HOPKINS UNIVERSITY & 502 & $2.560 \%$ \\
\hline 5 & HARVARD UNIVERSITY & 486 & $2.478 \%$ \\
\hline 6 & COUNTRYAL UNIVERSITY OF SINGAPORE & 478 & $2.438 \%$ \\
\hline 7 & MOORFIELDS EYE HOSPITAL NHS FOUNDATION TRUST & 462 & $2.356 \%$ \\
\hline 8 & SINGAPORE COUNTRYAL EYE CENTER & 450 & $2.295 \%$ \\
\hline 9 & UNIVERSITY OF CALIFORNIA SAN DIEGO & 430 & $2.193 \%$ \\
\hline 10 & DUKE UNIVERSITY & 393 & $2.004 \%$ \\
\hline 11 & UNIVERSITY OF MELBOURNE & 387 & $1.974 \%$ \\
\hline 12 & SUN YAT SEN UNIVERSITY & 361 & $1.841 \%$ \\
\hline 13 & VA BOSTON HEALTHCARE SYSTEM & 340 & $1.734 \%$ \\
\hline 14 & BASCOM PALMER EYE INSTITUTE & 330 & $1.683 \%$ \\
\hline 15 & WILMER EYE INSTITUTE & 312 & $1.591 \%$ \\
\hline 16 & CAPITAL MEDICAL UNIVERSITY & 309 & $1.576 \%$ \\
\hline 17 & UNIVERSITY OF MIAMI & 306 & $1.561 \%$ \\
\hline 18 & SEOUL COUNTRYAL UNIVERSITY & 293 & $1.494 \%$ \\
\hline 19 & MASSACHUSETTS EYE EAR INFIRMARY & 282 & $1.438 \%$ \\
\hline 20 & NEW YORK EYE EAR INFIRMARY OF MOUNT SINAI & 278 & $1.418 \%$ \\
\hline
\end{tabular}

Table 6 Top 20 journals in which most of the glaucoma articles were published in the SCIE during 2009-2018

\begin{tabular}{|c|c|c|c|}
\hline Rank & Journal & $\begin{array}{c}\text { Number of } \\
\text { articles }\end{array}$ & $\% / 19609$ \\
\hline 1 & INVESTIGATIVE OPHTHALMOLOGY VISUAL SCIENCE & 1848 & $9.416 \%$ \\
\hline 2 & JOURNAL OF GLAUCOMA & 1558 & $7.938 \%$ \\
\hline 3 & PLOS ONE & 773 & $3.938 \%$ \\
\hline 4 & OPHTHALMOLOGY & 683 & $3.480 \%$ \\
\hline 5 & AMERICAN JOURNAL OF OPHTHALMOLOGY & 537 & $2.736 \%$ \\
\hline 6 & BRITISH JOURNAL OF OPHTHALMOLOGY & 504 & $2.568 \%$ \\
\hline 7 & ACTA OPHTHALMOLOGICA & 461 & $2.349 \%$ \\
\hline \multirow[t]{2}{*}{8} & GRAEFES ARCHIVE FOR CLINICAL AND EXPERIMENTAL & 450 & $2.293 \%$ \\
\hline & OPHTHALMOLOGY & & \\
\hline 9 & EYE & 448 & $2.283 \%$ \\
\hline 10 & EXPERIMENTAL EYE RESEARCH & 368 & $1.875 \%$ \\
\hline 11 & MOLECULAR VISION & 333 & $1.697 \%$ \\
\hline 12 & CURRENT EYE RESEARCH & 324 & $1.651 \%$ \\
\hline 13 & INTERCOUNTRYAL JOURNAL OF OPHTHALMOLOGY & 318 & $1.620 \%$ \\
\hline 14 & EUROPEAN JOURNAL OF OPHTHALMOLOGY & 315 & $1.605 \%$ \\
\hline 15 & BMC OPHTHALMOLOGY & 291 & $1.483 \%$ \\
\hline 16 & JOURNAL OF OPHTHALMOLOGY & 280 & $1.427 \%$ \\
\hline 17 & INDIAN JOURNAL OF OPHTHALMOLOGY & 256 & $1.304 \%$ \\
\hline 18 & CLINICAL AND EXPERIMENTAL OPHTHALMOLOGY & 251 & $1.279 \%$ \\
\hline 19 & CORNEA & 245 & $1.248 \%$ \\
\hline 20 & OPHTHALMOLOGE & 245 & $1.248 \%$ \\
\hline
\end{tabular}

Table 7 The top 20 funding agencies during 2009-2018 


\begin{tabular}{|c|c|c|c|}
\hline Rank & Field: Funding Agency & $\begin{array}{l}\text { Number of } \\
\text { articles }\end{array}$ & $\% / 19609$ \\
\hline 1 & RESEARCH TO PREVENT BLINDNESS & 673 & $3.432 \%$ \\
\hline 2 & COUNTRYAL INSTITUTES OF HEALTH & 594 & $3.029 \%$ \\
\hline 3 & COUNTRYAL NATURAL SCIENCE FOUNDATION OF CHINA & 581 & $2.963 \%$ \\
\hline 4 & $\mathrm{NIH}$ & 474 & $2.417 \%$ \\
\hline 5 & COUNTRYAL EYE INSTITUTE & 443 & $2.259 \%$ \\
\hline 6 & ALLERGAN & 232 & $1.183 \%$ \\
\hline 7 & ALCON & 181 & $0.923 \%$ \\
\hline 8 & RESEARCH TO PREVENT BLINDNESS NEW YORK NY & 171 & $0.872 \%$ \\
\hline 9 & MEDICAL RESEARCH COUNCIL & 155 & $0.790 \%$ \\
\hline 10 & NEI NIH HHS & 153 & $0.780 \%$ \\
\hline 11 & PFIZER & 152 & $0.775 \%$ \\
\hline 12 & RESEARCH TO PREVENT BLINDNESS INC & 143 & $0.729 \%$ \\
\hline 13 & COUNTRYAL INSTITUTE FOR HEALTH RESEARCH & 132 & $0.673 \%$ \\
\hline 14 & $\begin{array}{l}\text { MINISTRY OF EDUCATION CULTURE SPORTS SCIENCE AND } \\
\text { TECHNOLOGY OF JAPAN }\end{array}$ & 117 & $0.597 \%$ \\
\hline 15 & FIGHT FOR SIGHT & 116 & $0.592 \%$ \\
\hline 16 & PFIZER INC & 114 & $0.581 \%$ \\
\hline 17 & RESEARCH TO PREVENT BLINDNESS INC NEW YORK NEW YORK & 113 & $0.576 \%$ \\
\hline 18 & RESEARCH TO PREVENT BLINDNESS NEW YORK NEW YORK & 101 & $0.515 \%$ \\
\hline 19 & HEIDELBERG ENGINEERING & 99 & $0.505 \%$ \\
\hline 20 & NIH NEI & 99 & $0.505 \%$ \\
\hline
\end{tabular}

Table 8 Distribution of journals' impact factors

\begin{tabular}{cccc}
\hline Influence factor distribution interval & Number of articles & \%/19609 \\
\hline & $\geq 50$ & 5 & $0.025 \%$ \\
& $\geq 40<50$ & 9 & $0.046 \%$ \\
$\geq$ & $30<40$ & 3 & $0.015 \%$ \\
& $\geq 20<30$ & 20 & $0.102 \%$ \\
$\geq$ & $10<20$ & 135 & $0.688 \%$ \\
& $\geq 5<10$ & 1425 & $7.267 \%$ \\
& $\geq 3<5$ & 5679 & $28.961 \%$ \\
& $\geq 2<3$ & 4414 & $22.510 \%$ \\
$\geq 1<2$ & 5629 & $28.706 \%$ \\
& $\geq 0<1$ & 1712 & $2.731 \%$ \\
No impact factor & 578 & $2.948 \%$ \\
\hline
\end{tabular}

\section{Figures}




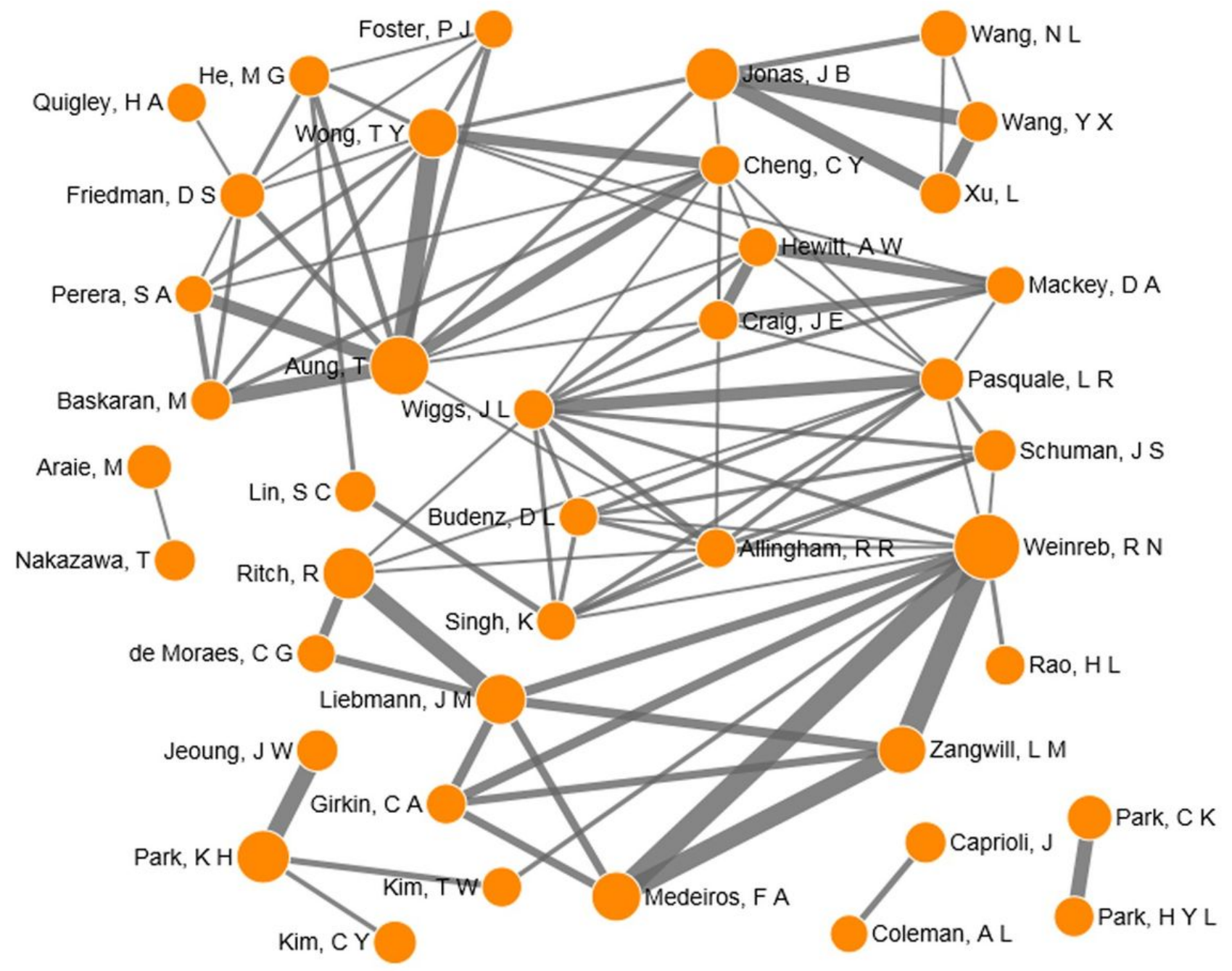

Figure 1

The co-occurrence matrix of the top 50 authors in the number of articles 


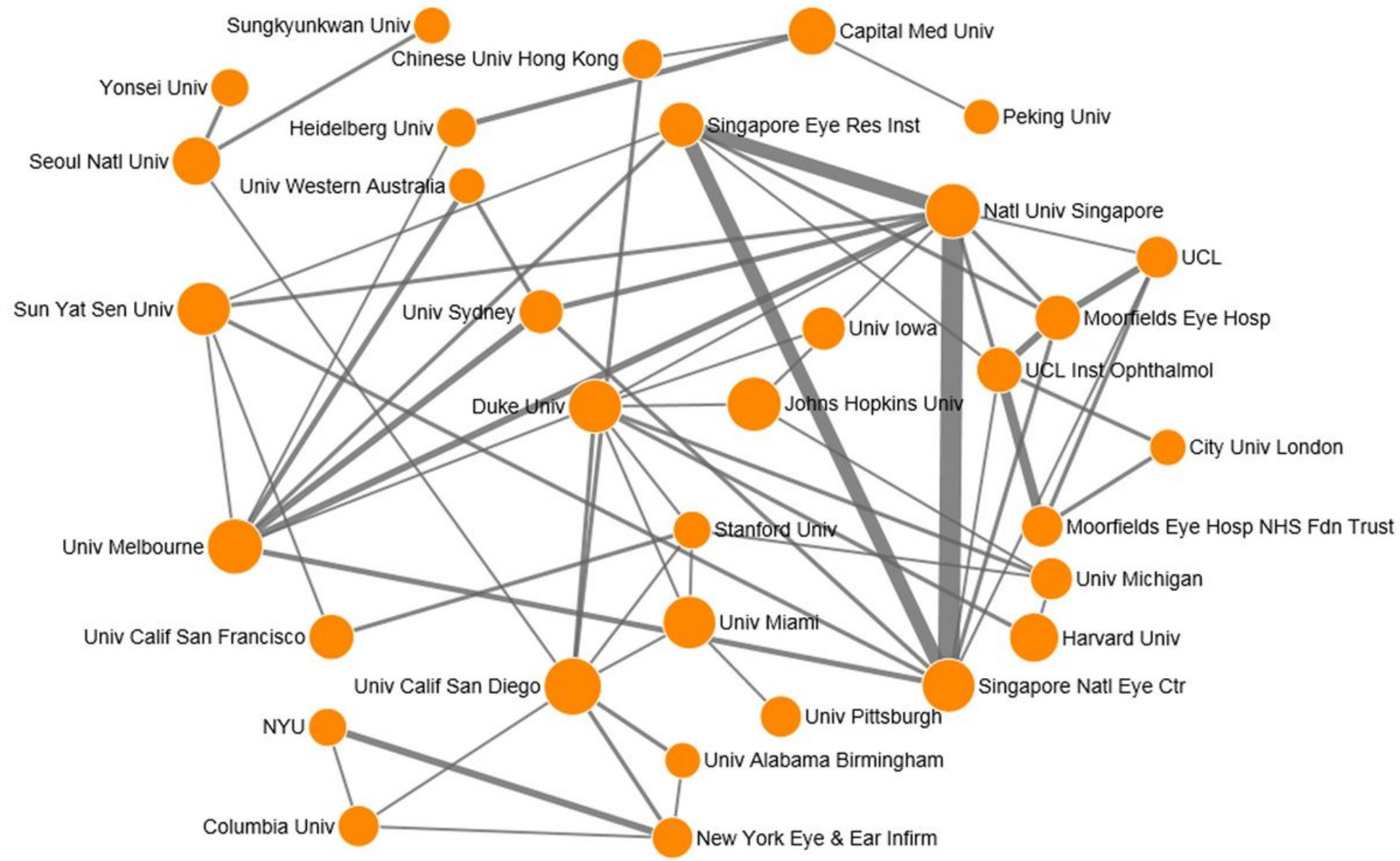

Figure 2

The co-occurrence matrix of the top 50 author's institutions in the number of articles (organization only) 


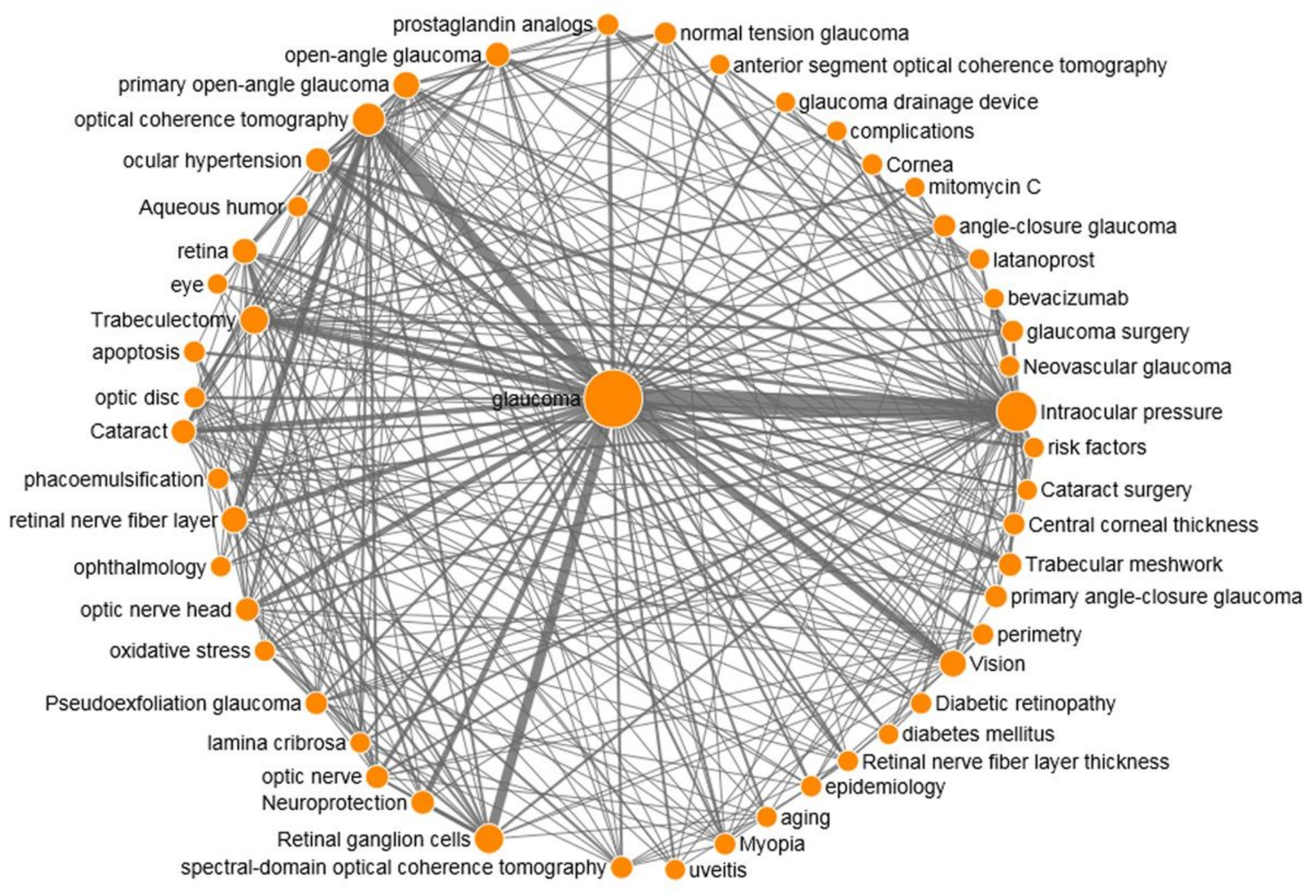

Figure 3

The co-occurrence map of the top 50 keywords appeared most in the articles.

\section{Supplementary Files}

This is a list of supplementary files associated with this preprint. Click to download.

- PRISMA2009ChecklistMSWord.doc 